Article

\title{
Interactions among Shade, Caching Behavior, and Predation Risk May Drive Seed Trait Evolution in Scatter-Hoarded Plants
}

\author{
Nathanael I. Lichti ${ }^{1, *(\mathbb{D}, \text { Harmony J. Dalgleish }}{ }^{2}$ and Michael A. Steele ${ }^{3}$ \\ 1 Department of Statistics, Purdue University, 250 N. University Street, West Lafayette, IN 47907, USA \\ 2 Department of Biology, College of William and Mary, 540 Landrum Drive, Williamsburg, VA 23185, USA; \\ hjdalgleish@wm.edu \\ 3 Department of Biology, Wilkes University, 84 West South St., Wilkes-Barre, PA 18766, USA; \\ michael.steele@wilkes.edu \\ * Correspondence: nlichti@purdue.edu
}

Received: 7 June 2020; Accepted: 28 October 2020; Published: 31 October 2020

\begin{abstract}
Although dispersal is critical to plant life history, the relationships between seed traits and dispersal success in animal-dispersed plants remain unclear due to complex interactions among the effects of seed traits, habitat structure, and disperser behavior. We propose that in plants dispersed by scatter-hoarding granivores, seed trait evolution may have been driven by selective pressures that arise from interactions between seedling shade intolerance and predator-mediated caching behavior. Using an optimal foraging model that accounts for cache concealment, hoarder memory, and perceived predation risk, we show that hoarders can obtain cache-recovery advantages by placing caches in moderately risky locations that force potential pilferers to engage in high levels of vigilance. Our model also demonstrates that the level of risk needed to optimally protect a cache increases with the value of the cached food item. If hoarders perceive less sheltered, high-light conditions to be more risky and use this information to protect their caches, then shade-intolerant plants may increase their fitness by producing seeds with traits valued by hoarders. Consistent with this hypothesis, shade tolerance in scatter-hoarded tree species is inversely related to the value of their seeds as perceived by a scatter-hoarding rodent.
\end{abstract}

Keywords: directed dispersal; landscape of fear; mutualism; optimal density model; optimal foraging; Quercus; Sciurus; seed-seedling conflict

\section{Introduction}

The seed-seedling transition represents a critical juncture in plant life history and a central theme in plant demography, community ecology, and evolution, as well as ecosystem management and conservation [1] (and citations therein), [2]. In particular, seed dispersal reduces density-dependent competition and mortality near the maternal plant [3], determines the environmental conditions under which seedlings must function $[4,5]$, and, together with pollen dispersal, represents the main opportunity for gene flow in flowering plants. However, plants also experience high levels of mortality during dispersal. Seeds are killed by inhospitable abiotic conditions (e.g., desiccation, freezing), pathogens, and predation by granivorous insects, birds, or mammals [6,7], and further mortality is caused at the seedling stage by arrival in inhospitable locations [4]. Given these pressures, researchers dating back to Darwin [8] have considered selection for successful dispersal to be the principle driver of diversification in seed morphology and chemistry $[9,10]$. Yet, despite their importance to plant ecology and evolution $[1,5,11,12]$, the actual relationships between many seed phenotypes and dispersal success remain unclear. In particular, our understanding of the functional ecology and evolution of seed traits 
among species that are dispersed or eaten by animals has been constrained by our poor understanding of the complex feedbacks that exist among animal behavior, habitat variation, and seedling growth requirements $[13,14]$.

In this paper, we propose that the evolution of one common seed dispersal syndrome-dispersal by scatter-hoarding granivorous birds and rodents-may have been shaped by the joint selective pressures generated by three interacting ecological processes: shade effects on seedling competitiveness and growth, pilferage-avoidance by scatter-hoarding, granivorous animals, and habitat-mediated anti-predator behavior among those animals. Through a series of modelling exercises, we show that acting in concert, these processes can incentivize hoarders to direct highly valued seeds toward favorable seedling habitats, and that this behavior can create selective pressures to express seed traits that are useful to hoarders. We also present preliminary empirical evidence consistent with the proposed mechanisms.

\subsection{Seed Dispersal by Scatter-Hoarding Granivores}

The term "scatter-hoarding" refers to a food-storage strategy used by many seed-eating rodents and some seed-eating birds [15]. Rather than establishing a single, large store of food to survive the temperate winter or tropical dry season, scatter-hoarding animals create numerous, spatially dispersed caches, each of which contains only one or a few food items [16]. By relying on many small caches, the hoarders reduce the odds that a single catastrophic event will lead to starvation. However, because individual caches are not guarded, they may be pilfered (i.e., discovered and stollen) by other foragers. To reduce pilferage, scatter-hoarders conceal their caches-often by burying the cached items in the soil-and distribute their caches over a relatively wide area. Unless limited by available resources, they also store more food than required [16,17]. In years when food is abundant, many seeds may therefore remain in caches until germination [15,17-19].

Numerous studies have demonstrated that seeds' phenotypic traits (and thus the relative abundances of seeds with different traits in a neighborhood [20-22]) exert strong influences on caching frequency and seed dispersal by rodents (e.g., Dipodomys [23], Dasyprocta [24,25], Apodemus [26,27] and other Murids [28,29], Tamias [30-32], Sciurus [33-36], and other Sciurids [37,38]). From this work, we know that hoarders make seed-handling decisions that include which seeds to collect, whether to cache them or eat them immediately, the distances to which seeds are carried, and the microhabitats into which they are cached $[14,39,40]$. We also know that these decisions depend on the seed's size, energy and nutrient contents, physical and chemical defenses, and perishability (see reviews by $[9,14]$ ), as well as the total availability of seeds to consumers and the relative abundances of different seed types in the consumers' neighborhood $[38,41]$. Thus, mechanisms exist for plants to evolve seed traits that manipulate hoarder behavior to the plants' advantage [9].

\subsection{Scatter-Hoarding as a Behavioral and Evolutionary Strategy}

For scatter-hoarding to emerge as an evolutionarily stable strategy, competing hoarders must either maintain a significant advantage over other animals in recovering their own caches [42], or they must maintain caches as a quasi-communal resource through a system of reciprocal pilferage [43]. Many scatter-hoarding animals possess exceptional spatial memories [44], allowing them to actively manage and selectively consume their caches over periods ranging from hours to years [45-47]. However, while memory does confer a recovery advantage in at least some cases (e.g., [48-50]), pilferage remains a risk, even in these systems [43,51]. To maintain their recovery advantage, hoarders must therefore avoid cache-pilferage in addition to facilitating cache recovery.

By concealing their caches and distributing them over a relatively wide area, hoarders can reduce the rate at which pilfering foragers are rewarded and increase the probability that would-be pilferers will change foraging strategies or move to a new location $[52,53]$. Specifically, hoarders space caches at densities that balance the cache's expected value at recovery against the investment required to place the cache in a particular location. Because wider distributions require greater investment in movement, 
seeds that are perceived to be more valuable, either because of their inherent traits or as a result of resource scarcity, are cached at lower densities [35,52,54].

Although it has received less attention, hoarders should also be able to manage pilferage risk by manipulating cache detection rates $[46,55]$ or by forcing pilferers to pay extra costs to search for a cache. In particular, placing caches in locations with less vegetative cover can increase pilferers' perceived risks of predation [56,57], and should therefore reduce the risk of cache loss. Hoarders would also pay additional costs to use these locations. However, their ability to remember cache locations should allow them to recover caches more quickly and should therefore reduce their exposure relative to the risks faced by naive searchers.

Although it is not yet conclusive, evidence to support the hypothesis that hoarders utilize the landscape of fear to help avoid cache-pilferage has been found in several systems. For instance, Merriam's kangaroo rats (Dipodymys merriami) in a laboratory setting established caches in dark (i.e., low-risk) locations, but increased their use of more illuminated locations after some of the caches were pilfered by researchers [58]. Similarly, Algerian mice (Mus spretus) increased their use of exposed cache locations in years of low seed availability, when competition from pilfering conspecifics was more intense [59]. Finally, Steele et al. [60,61] found that eastern gray squirrels (Sciurus carolinensis) are less likely to pilfer seeds placed outside of the forest canopy, where they exhibit higher giving-up densities. The squirrels were also more likely to cache high-value seeds in such locations than lower-value seeds.

Given that rodents tend to associate risk with more open, well-lit microsites, the possibility that they might leverage predation risk to protect their caches could have important implications for seed trait evolution. Specifically, we hypothesize that if foragers are willing to accept greater risks to pilfer more valuable caches, then hoarders should also accept greater risks to protect those caches, provided that the risks do not also preclude retrieval. As a result, plants that express more valuable seed traits may be directed toward more open locations. In shade-intolerant plant species, the resulting benefits to any seedlings that escape from caches could therefore generate selective pressure for traits valued by hoarders.

To explore these interactions, we introduce a foraging model that quantifies the benefits that a forager can achieve with a given foraging strategy (primary foraging, pilfering of others' caches, or retrieval of one's own caches), conditional on its current motivational state (hunger versus satiation), and its perceived risk of predation, as well as the density of prey items and the inherent traits (e.g., energy content) and states (cached versus freely available) of those prey items. Behavioral variables in the model include the rate at which the forager searches for food, its allocation of time and attention to vigilance versus foraging and to different foraging strategies, its acceptance of detected prey, and its allocation of those prey to storage versus immediate consumption. The model also recognizes a difference between the process of foraging for new food items and retrieval of items that the forager has previously stored.

Our current analysis has three goals. First, we want to understand how the risk of predation affects the relative efficiency of two different foraging strategies: retrieval of one's own caches, versus pilfering of caches created by other hoarders. If foragers can still retrieve caches at risk levels where pilferers cannot operate, then at least in theory, hoarders will be able to exclude pilferers by placing caches in those moderately risky locations. Because the benefits of foraging depend on the forager's state as well as the way that it uses harvested food items, we compare foraging strategies across a range of hunger states. Second, we want to understand how the level of risk required to protect a cache relates to the value of the cached item. If greater levels of risk are required to protect more valuable items, then a plant's investment in seed traits valued by hoarders could induce those hoarders to place the seeds in riskier, potentially more open locations. The fitness benefits of such an investment to the plant would correlate with its sensitivity to shade. Therefore, to provide a preliminary check of the model's implications for seed trait evolution, we use previously published data to investigate the relationship between shade tolerance and seed utility as perceived by eastern gray squirrels. 


\section{Materials and Methods}

\subsection{Study System}

Although we expect the relationships modeled here to apply to scatter-hoarding systems generally, we have parameterized the model based on data from eastern gray squirrels and northern red oak (Quercus rubra) acorns in eastern North America, primarily from the Kirby Park system in northeastern Pennsylvania (see site details in $[33,50,60,61]$ ). The site consists of an open, urban park with clusters of mature northern red oak and pin oak (Q. palustris). Squirrels in this system maintain a recovery advantage for their own caches, despite high densities of conspecific pilferers, and the removal of hoarders through live-trapping has been found to extend seed residence times in those hoarders' caches [50]. Squirrels in this system also move more highly valued seeds into areas with less cover and higher giving-up densities more frequently than they move less-valued seeds into these locations [60,61].

\subsection{Model Description}

Our model combines elements from Holling's [62] disk equation, models for the effect of fear on foraging behavior [57,63], and models for the effects of prey crypsis [64]. To minimize notation and model complexity, we consider a single seed species here, and we assume that all seeds in a given species possess similar traits (i.e., properties inherent to the seed, such as energy content). However, we recognize three distinct seed states: uncached, "free" seeds, seeds that were previously cached by a focal animal, and seeds that were previously cached by another individual. The model is readily expanded to include multiple seed species or multiple phenotypes within a species, including combinations of multiple traits.

We define the per capita base consumption rate for seed state $i$ as,

$$
f_{i}=\frac{r_{i} d_{i} p_{i} n_{i}}{1+\sum_{i}\left(T_{i}+E_{i}+H_{i}\right)}
$$

where $r_{i} \geq 0$ is the forager's search rate in units of area per unit time, $d_{i}$ is the proportion of seeds in state $i$ that the forager detects when it encounters them (see Equation (5) for details), $p_{i}$ is the proportion of detected seeds from state $i$ that are accepted or utilized by the forager, and $n_{i}$ is the density of seeds in state $i$. We assume that there are two basic search rates in the current model; the first applies to free seeds and other individuals' caches, while a second, potentially faster rate applies to retrieval. We can therefore express $r_{i}=r m_{i}$, where $r$ is a base rate and $m_{i}$ is a memory-modifier that is fixed at 1 for seeds that the focal animal did not previously cache and can take values $\geq 1$ for caches that the hoarder is retrieving. In the denominator, we have broken handling time out into three separate terms, $T, E$, and $H$, which describe the time taken to travel during retrieval, excavate caches, and handle seeds after harvest, respectively. These terms are detailed in Equations (2)-(4).

Equation (1) is mathematically equivalent to previous extensions of the disk equation that have accounted for the effects of prey crypsis and vigilance. In the numerator, the product $r_{i} d_{i}$ represents the standard attack rate, which Holling [62] defined as the product of the forager's search rate and the probability of detecting a prey item of type $i$. Breaking the attack rate out into its constituent parts allows the model to account for differences in detectability among prey types while maintaining a constant areal search rate [64]. As explained in Equation (5), vigilance against predators reduces the amount of attention available for foraging and lowers the prey detection probability, $d_{i}$. This formulation also follows [64], but is equivalent to the model used by [63] (see Supplementary Materials for details).

We model the time spent traveling to cache locations during retrieval as,

$$
T_{i}=\frac{o_{i}}{t \sqrt{\pi}} r_{i} d_{i} \sqrt{n_{i}}
$$


where the parameter $t$ describes the hoarder's linear rate of travel, and $o_{i}$ is an indicator that is equal to 1 if state $i$ describes the forager's own caches and 0 otherwise. Equation (2) assumes that during retrieval, the forager travels in a straight line to the approximate location of the nearest cache and then executes an area-constrained search at the areal rate $r_{i}$. It also assumes that no other foraging occurs while the animal travels. See Supplementary Materials for details.

The time that the forager spends excavating caches is proportional to the number of cached seeds that are detected,

$$
E_{i}=e c_{i} r_{i} d_{i} n_{i}
$$

where $e$ is the time required to excavate a cache and the indicator $c_{i}=1$ if seed type $i$ is cached, and 0 otherwise. Caches are only excavated if they have been detected, so $c_{i}$ makes no distinction between pilfering and retrieval. The acceptance rate, $p_{i}$, does not appear in Equation (3) because caches must be excavated before their contents can be assessed or accepted. This assumes that hoarders do not remember the contents of their caches.

Once an item has been collected and accepted, it may be used in a variety of different ways. For instance, seeds may be eaten immediately or cached for future use, and different uses may imply very different handling times. We use $w_{i j}$ to indicate the proportion of accepted seeds of type $i$ that are allocated to use $j$, where $0 \leq w_{i j} \leq 1$ and $\sum_{j} w_{i j}=1$. Then, letting $h_{i j}$ indicate the handling time associated with seed type $i$ and use $j$, we calculate the total post-collection handling time as,

$$
H_{i}=r_{i} d_{i} p_{i} n_{i} \sum_{j} w_{i j} h_{i j}
$$

Scatter-hoarded seeds are concealed by the hoarder and therefore represent cryptic prey items from the perspective of would-be pilferers. However, they may be much less cryptic from the perspective of cache-owners. To model this relationship, we follow the approach of [64], who define the probability of detection for a given seed as a function of the forager's current search rate relative to a maximum rate, $R_{i}$, the conspicuousness of the seeds' state, $K_{i}$, the proportion of the forager's attention to searching that is dedicated to seeds in that state, $A_{i}$, and the proportion of attention to vigilance, $v$,

$$
d_{i}=\left\{\begin{array}{cc}
\left(A_{i}(1-v)\right)^{1 / K_{i}}\left(1-\left(\frac{r_{i}}{R_{i}}\right)^{K_{i}}\right) & r_{i}<R_{i} \\
0 & \text { otherwise }
\end{array}\right.
$$

This formulation makes several reasonable assumptions. First, foragers can detect a larger proportion of the prey items that they encounter if they search an area more slowly, and they cannot detect anything if they move through an area too rapidly. Thus, a tradeoff exists between the forager's ability to search a given microsite thoroughly and its ability to search a larger area. Provided that hoarders can remember their cache locations, the maximum rate for retrieval, $R_{\text {own }}$, is assumed to be larger than for other prey states (see Supplement S1 for details). Second, conspicuous items $\left(K_{i}>1\right)$ are generally easier to detect than cryptic items $\left(0<K_{i}<1\right)$, and therefore require less active attention for detection. Third, dedicating active attention to a search can improve detection, but only up to a point. Although high levels of attention benefit all searches, the benefits are proportionally greater for cryptic items than for conspicuous items, since the later are already detected at high rates. Finally, dedicating some proportion of attention to vigilance necessarily diverts cognitive resources from searching and causes detection probabilities to decline. Again, searches for cryptic prey are more strongly affected than searches for conspicuous prey.

In their original paper, Dukas and Ellner [64] defined the coefficient $A_{i}$ in Equation (5) as the proportion of the forager's attention that was dedicated to searching for prey type $i$, where $0 \leq A_{i} \leq 1$, and $\sum A_{i}=1$. However, we suggest that foragers are more likely to allocate attention to foraging strategies that reflect prey states rather than individual prey types. For instance, a scatter-hoarder might reasonably divide its attention between three strategies-primary collection of seeds that are 
freely available, locating and pilfering other individuals' caches, or recovering its own caches-and then adjust its use of these strategies based on their relative profitabilities. In contrast, dedicating specific attention to each individual prey type (i.e., a particular species in a given state) would greatly increase the cognitive load placed on the forager; instead of $M$ strategies, it would need to optimize over $N$ species $\times M$ state combinations when reallocating its attention. By allowing foragers to allocate their attention to general search strategies instead of individual prey types, we ensure that attention and acceptance $\left(A_{i}\right.$ and $\left.p_{i}\right)$ remain separable in models with multiple prey species. We also avoid the problematic assumption that naive foragers somehow recognize a cache's contents before they excavate it. Instead, we assume that all detected caches are excavated, and that their contents are then accepted and used, or not, based on the acceptance rate, $p_{i}$.

Equations (1)-(5) define the rates at which seeds are physically collected and allocated to caches or consumption. However, the perceived benefit of foraging will not vary as a fixed proportion of the seed utilization rate. Instead, the benefits perceived by a forager depend on the forager's state, the seeds' traits, and the manner in which seeds are used [65]. For example, if an animal is currently hungry, then the perceived benefit of consuming one unit of energy would be greater than the benefit derived by caching it. However, this relationship may be reversed if the animal is satiated. To account for these relationships, we define the perceived net benefit of foraging as,

$$
U_{\text {forage }}=\sum_{i}\left(f_{i} \sum_{k} x_{i k}\left(\sum_{j} w_{i j} g_{i j k}\right)\right)-C(1-v)
$$

where $f_{i}$ is the base usage rate for seeds of type $i$, as defined in Equation (1), $x_{i k}$ is the value that seed type $i$ expresses for trait $k$ (e.g., energy content), $w_{i j}$ describes usage, as defined in Equation (4), and $g_{i j k}$ describes the marginal utility of applying one unit of trait $k$ from source $i$ to use $j$ (e.g., one kilojoule of energy from a new seed to immediate consumption). The second term in Equation (6) describes the utility cost associated with the forager's perceived risk of predation under local habitat conditions. This cost is described by the utility rate $C$, which describes the foraging location and is discounted proportional to vigilance. Locations with higher values for $C$ are perceived to be riskier.

Utility is a standardized metric that quantifies an animal's willingness to forgo one potential benefit in order to obtain some other benefit, or, potentially, to avoid a perceived harm. Thus, Equation (6) describes the tradeoff that foragers must make between perceived foraging benefits and safety. Although our formulation is similar to others (e.g., [63]), it focuses on small-scale decisions and proximate rather than ultimate causes of behavior. Where Brown [63] assesses costs based on true predation risk, we envision a more general perceived cost that may reflect the actual risk of predation, or may correlate more strongly with habitat variables such as cover [66]. In addition, the marginal utility terms $\left(g_{i j k}\right)$ in Equation (6) account the forager's motivational state (and by extension, its physiological condition), as well as prey traits, prey usage, and perceived risk.

To compare the behavior of hungry versus satiated foragers, we define the act of caching $1 \mathrm{~kJ}$ of energy to have a fixed utility $g_{[i, \mathrm{cache}, \mathrm{kJ}]}=1$ and then define all other values relative to this benchmark. For instance, greater $g$-values for ingestion of energy reflect increasing hunger and favor the allocation of seeds to consumption versus storage. All else being equal, high $g$-values for energy consumption will also increase the perceived benefit of foraging at a given risk level $(C)$, and will therefore lead foragers to utilize locations that they would otherwise avoid. In the context of a dynamic model, this structure will also allow for feedbacks between the rate of consumption of energy, nutrients, or secondary compounds at time $t$ and the value attached to further consumption at $t+\Delta t$. By indexing $g_{i j k}$ according to seed state, $i$, as well as use, $j$, and trait value, $k$, we allow for the possibility that foragers may differentiate among seeds based on their origins. For instance, hoarders might attach less value to the act of recaching their own seeds than to storing new seeds. 


\subsection{Analysis}

Our analysis of the model presented in Section 2.2 contrasts the maximum benefit rates that can be achieved under a given set of conditions by pilferers verses retrievers. Specifically, we divide the model's parameters into two classes: contextual variables and behavioral variables. The contextual variables include risk $(C)$, seed energy content $(x)$, cache density $(n)$, and forager states $(g)$. They remain fixed within any given scenario but are varied systematically among scenarios in a factorial design. In contrast, we optimized the behavioral variables, including search rates $(r, m)$, vigilance $(v)$, and allocation of harvested resources $(w)$, within each scenario. In our main analyses, we fixed the proportion of attention dedicated to different search strategies $\left(A_{i}\right)$ to reflect the target strategy (retrieval or pilferage). However, we also ran a third replicate for each scenario, in which the proportions in $A$ were optimized with other behavioral variables, allowing the forager to choose among search strategies. Results for the third replicate appear in Figure S1. Acceptance rates $(p)$ only become relevant in scenarios where more than one type of food item is available. Since this did not apply in any of our current analyses, we fixed $p_{i}=1$ for all scenarios.

\subsubsection{Comparison of Foraging Strategies under Predation Risk}

For the first goal, we defined a suite of scenarios that varied the risk coefficient $\left(\log _{10} C=-2\right.$ to 3 in 0.02 unit increments), the density of an individual's caches $\left(n_{\text {own }}=0.02,0.12\right.$, or 0.32 seeds $\left./ \mathrm{m}^{2}\right)$, seed energy content $(x=5,35$, or $65 \mathrm{~kJ} /$ seed $)$, and hunger $\left(g_{[\mathrm{i}, \text { eat, } \mathrm{kJ}]}=0.2,1\right.$, or 5$)$ in a factorial combination. The relative benefit of recaching one $\mathrm{kJ}$ from the forager's own cached seeds was set to $g_{[\mathrm{own}, \text { cache, } \mathrm{kJ}]}=0.1$, versus 1 for caching newly acquired seeds. Then, for each scenario, we optimized Equation (6) with respect to the behavioral variables $\theta=(r, m, v, w)$ under two conditions. Under the first condition, we set the density for other animal's caches and free seeds to zero, and fixed $A_{\text {own }}=1$. This allowed us to calculate the maximum possible benefit of a retrieval strategy under the context defined by the scenario. Similarly, the second condition modeled a strategy of pure pilferage, with $A_{\text {other }}=1$. In this case, we set the focal animal's cache density and free seeds to zero and set the density of "other" caches to $5.9 \times$ the nominal density, $n_{\text {own }}$. We used a factor of 5.9 because eastern grey squirrels have an approximate population density of 6.9 individuals/ha and a home range of approximately 1 ha [67], implying that the focal animal would have access to caches established by 5.9 other squirrels. In all cases, we fixed $e=30 \mathrm{~s}, R_{i}=0.2 \mathrm{~m}^{2} / \mathrm{s}$ for primary foraging and pilfering, $R_{\text {retrieval }}=6.366 \mathrm{~m}^{2} / \mathrm{s}, K_{\text {own }}=1$ for an individual's own caches, and $K_{\text {other }}=0.9$ for other caches. The maximum search rate for retrieval was based on the assumption that squirrels can remember cache locations to within approximately $10 \mathrm{~cm}$ and can therefore concentrate their searches within a smaller area. Based on data from [33], handling time was fixed at $85 \mathrm{~s} / \mathrm{seed}$ for caching, and was assumed to vary proportionally with energy content for eating, at a value of $x \times 375 / 60 \mathrm{~s} / \mathrm{seed}$. Travel speed was set to $t=3 \mathrm{~m} / \mathrm{s}$, a moderate pace for eastern grey squirrels. Overall, these represent relatively pessimistic assumptions for retrieval versus pilferage.

Optimization of Equation (6) with respect to the behavioral parameter vector $\theta$ was performed in $\mathrm{R}$, v. 3.6.3 [68] using the bounded BFGS algorithm of [69] (i.e., method "L-BFGS-B" in the optim function) applied to linearized versions of the parameters. This is a box-constrained numerical optimization routine that uses an iterative approach to locate the local maximum of a given objective function with respect to a parameter vector. In the event that the L-BFGS-B algorithm failed to yield a solution, we fell back on the more robust but considerably slower differential evolution algorithm of [70]. This routine locates global optima by simulating mutation and natural selection within a population of parameter vectors, where the objective function to be optimized defines "fitness".

The optimizations yielded a pair of matched curves for each scenario. The first described the maximum benefit that a forager could achieve using retrieval, and the second described the potential benefit of pilferage. To determine the degree to which hoarders might enjoy a retrieval advantage, we graphed the difference between these curves, $U_{\text {retrieval }}-U_{\text {pilfer, }}$ against risk for each scenario. Assuming that foragers seek to maximize their benefits, increasingly positive differences will 
correspond with greater use of the retrieval strategy and a greater retrieval advantage for caches that have been established under the modeled conditions.

We also compared the original benefit curves to a hypothetical giving-up rate, following from [56]. Foragers generally will not persist in exploiting a resource when other, potentially more profitable options exist $[56,71]$. The giving-up rate represents the forager's expected benefit of foraging elsewhere, and is determined by the overall abundance of resources in the forager's environment. If the benefit rate for a given strategy falls below the giving-up threshold, then the strategy is unlikely to be utilized under the conditions represented by the scenario in question. In addition, if the giving-up threshold intercepts the retrieval curve at a higher risk level than it intercepts the pilferage curve, then hoarders will be able to retrieve caches from risky locations where pilferage is excluded.

\subsubsection{Effects of Seed Value on the Risk Level Needed to Protect a Cache}

By itself, a finding that the benefits of retrieval exceed the benefits of pilfering in risky habitats will not be sufficient to show that hoarders can exert selective pressure on plants. For caching in risky locations to push seed trait evolution toward phenotypes favored by scatter-hoarders, the level of risk required to protect a cache must be positively related to the fitness of the cached seeds as well as seed value. A relationship between risk and fitness may be reasonably assumed for plants whose seedlings fail to thrive under shaded conditions. To examine the second relationship, we used our modeling results to graph a set of three isopleths in the phase plane for risk and seed value. The first isopleth represented the combination of risk and seed energy content at which the difference in potential benefits of retrieval versus pilfering $\left(U_{\text {retrieval }}-U_{\text {pilfer }}\right)$ was maximized. The other two isopleths showed the risk and seed-energy levels at which foraging returns under a given strategy intercepted our hypothetical giving-up threshold. Provided that the isopleth for retrieval falls to the right of the pilferage isopleth, the region between them represents a combination of risk and seed value where pilferage competition will be negligible.

\subsubsection{Seed Traits and Shade Tolerance}

If the evolution of scatter-hoarded seeds has been influenced by the selective mechanisms posited in this paper, then we would expect to see a negative relationship between a plant's ability to compete and grow in shaded environments, and its expression of traits that make its seeds valuable as cached resources for scatter-hoarding animals. As a preliminary test of this hypothesis, we used nonlinear least squares to regress the shade tolerance indices for 20 potentially scatter-hoarded tree species against the estimated utility of their seeds for caching.

We calculated utility for 20 hardwood species that are dispersed by scatter-hoarding rodents using data and methods from [72,73]. Seedling shade tolerance data were obtained from [74], who report shade tolerance measures on a five-point scale that has been broadly applied in North America. In this scale, 1 corresponds to very intolerant of shade; 2 , intolerant; 3 , moderately tolerant; 4 , tolerant; 5 , very tolerant. These values correspond to light availabilities expressed as percentage of full sunlight as follows: $1,>50 \% ; 2,25-50 \% ; 3,10-25 \% ; 4,5-10 \% ; 5,2-5 \%$. The shade tolerance classifications are based on empirical data for seedling survival and growth in shade, supplemented by foresters' expert opinion on species biology.

\section{Results}

\subsection{Comparison of Foraging Strategies under Predation Risk}

The results from our model appear in Figure 1, which illustrates the maximum foraging benefit that can be achieved by retrieval (blue lines) versus pilfering (red lines) as a function of perceived predation risk ( $x$-axis), seed energy content (line styles), cache density (increasing across grid rows from top to bottom) and forager hunger (increasing across columns from left to right). As expected, the potential benefits of foraging are larger for more energy-rich seeds, are greatest under low-risk 
conditions, and decline from left to right in each panel as increasing risks require greater investment in vigilance (see Figure S2). Benefits also increase with cache density from the top row to the bottom row. As predicted by [52], this effect is markedly stronger for pilfering than for memory-based retrieval, which allows more efficient foraging under low density conditions. Finally, the benefits of retrieval increase strongly as hunger increases from the left column to the right column. In contrast, the benefits of pilfering remain largely unchanged with respect to hunger. In this case, the different responses arise from differences in seed-usage decisions. Caching a seed requires less handling time than would be required to eat the same seed [33], and the curves in Figure 1 assume that recaching a seed will return only $1 / 10$ the utility of caching a new seed. As a result, the optimal usage decision (encoded by $w_{i j}$ ) under retrieval shifts from caching at $g_{\text {eat }}=0.2$ to consumption at $g_{\text {eat }}=5$. Under pilferage, caching continues to be more profitable than consumption under almost all of the modeled hunger conditions, and seeds are only consumed when the forager is hungry and operating under relatively high-risk conditions (Figure S3).

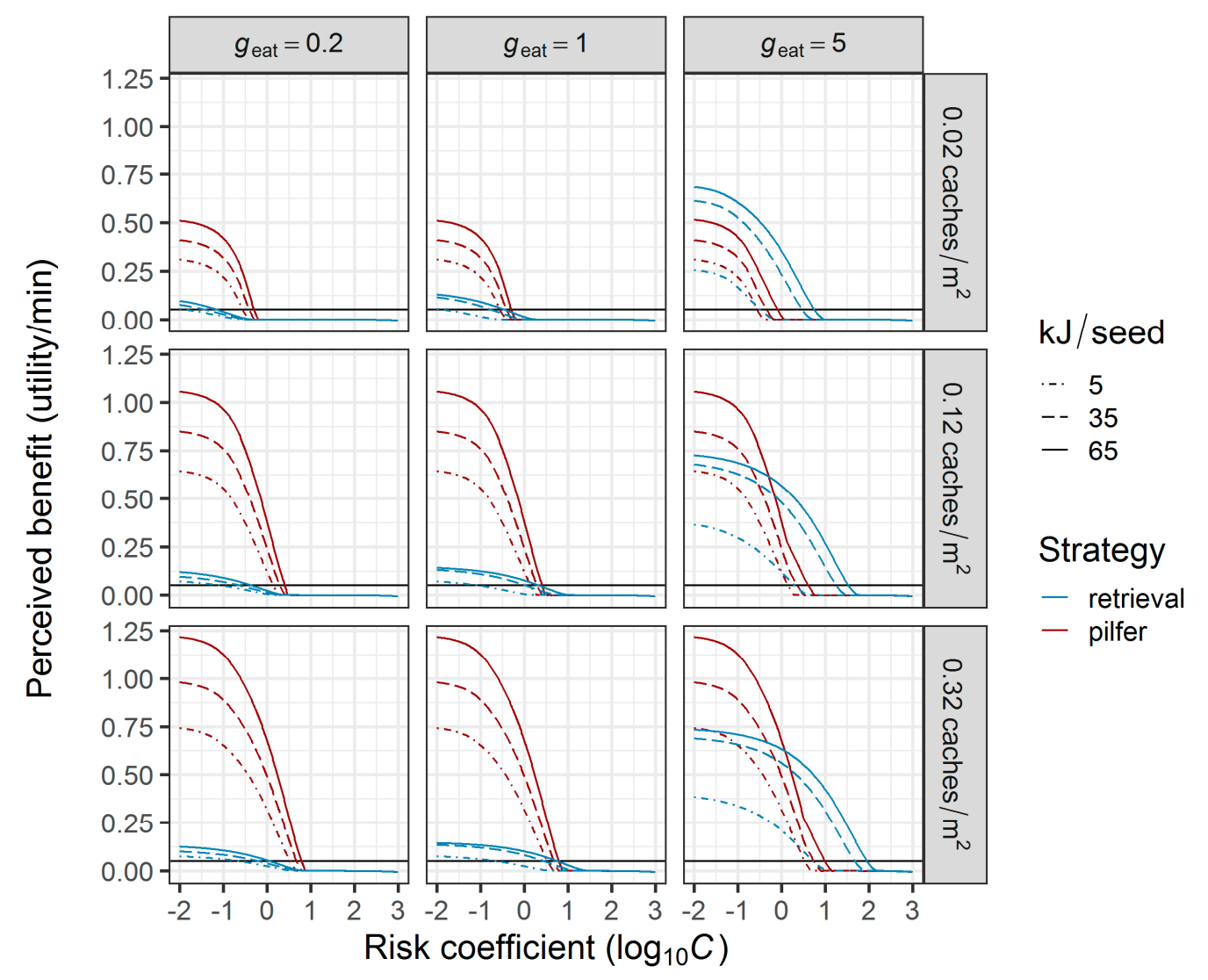

Figure 1. Maximum perceived benefit of foraging (utility) as a function of the perceived riskiness of the foraging location ( $x$-axis), the value of cached seeds (line styles), cache density (rows), and forager condition (columns; hunger increases from left to right). Colors show results for a forager that recovers its own caches (blue) versus pilfering caches made by other animals (red). Curves show the optimal results under a given set of conditions. The horizontal black line in each panel indicates a hypothetical giving-up threshold, below which animals will stop exploiting the current location and move elsewhere.

The curves in Figure 2 illustrate differences between the respective retrieval and pilfering curves seen in Figure 1. Assuming that foragers lack perfect information, we would expect them to employ a mixed strategy of pilfering and retrieval when this difference is equal to zero [14,75]. At negative values, pilfering will dominate, and at positive values, pilferage will dominate, with the degree of dominance dependent on the magnitude of the difference. Thus, increasingly positive values indicate 
greater relative retrieval advantages. Arrows indicate the risk levels at which the $65 \mathrm{~kJ}$ curves crossed the hypothetical giving-up threshold illustrated in Figure 1 by the black horizontal line in each panel.

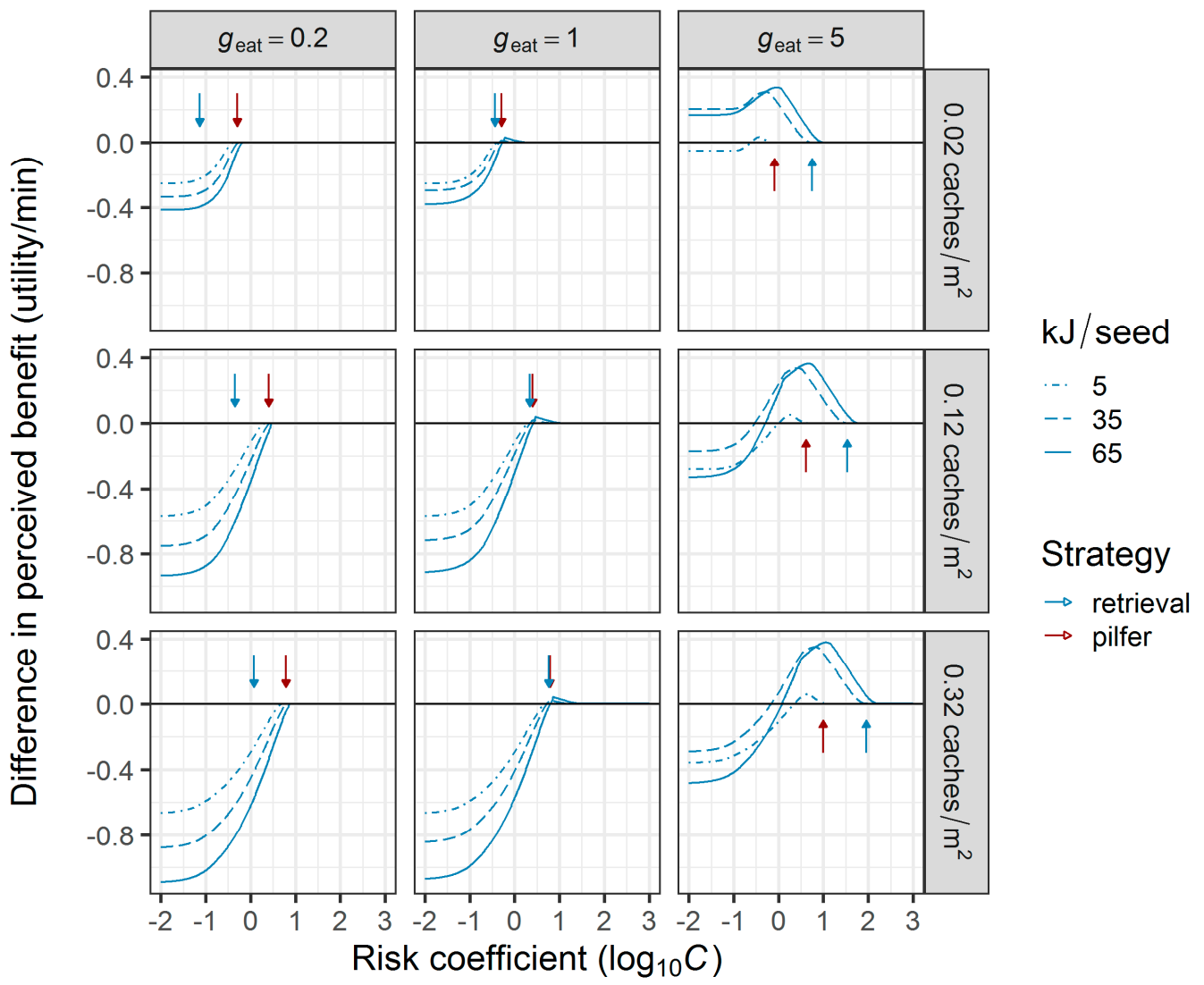

Figure 2. The difference between the benefit of retrieval and the benefit of pilferage (i.e., the difference between corresponding blue and red curves in Figure $1 ; y$-axis) is maximized at moderate risk levels ( $x$-axis) and becomes positive when foragers are hungry (right column) versus satiated (left column). The risk level that maximizes the advantage of retrieval increases with both seed value $(\mathrm{kJ} / \mathrm{seed})$ and cache density. Arrows indicate the risk level at which the benefits associated with each foraging strategy fall below the giving-up threshold shown by the black line in Figure 1 (only the results for $65 \mathrm{~kJ} / \mathrm{seed}$ are shown). This giving-up risk threshold is insensitive to forager condition for pilferage, but increases with hunger for retrieval. As a result, hungry retrievers may exploit risky locations that are avoided during pilferage.

As risk increases within each panel in Figure 2, the difference between the potential benefits of retrieval and pilfering initially moves in a positive direction, and then declines toward zero as increasing risks render both strategies nonviable. However, the implications of these movements are strongly dependent on forager condition. In the left-most column, the potential benefits of pilfering experienced by satiated foragers equal or exceed the benefits of retrieval, regardless of seed energy content or cache density. As a result, satiated animals should always favor pilfering over retrieval, especially under low-risk conditions. Provided that lower-risk alternatives are available, satiated foragers are also unlikely to exploit higher risk neighborhoods that provide few benefits, especially when cache densities are low. This is illustrated by the red arrows in Figure 2, which indicate giving-up thresholds for risk and consistently fall at low or moderate risk levels.

As foragers become hungrier, the benefits of pilfering remain stable, while the benefits of retrieval increase due to the forager's shift in usage from recaching, which provides relatively little benefit under any circumstance, to eating, which provides much greater benefit when animals are hungry. Consequently, the giving-up thresholds for risk converge in the middle column, where the utility 
gained by eating a seed matches that gained by caching a seed (i.e., $g_{\text {eat }}=1$ ), and become inverted in the right-most column, where the retrieval threshold exceeds the pilfering threshold. When foragers are hungry, retrieval also becomes the dominant strategy at moderate risk levels and lower cache densities, with a peak advantage over pilfering that occurs at higher risk levels for seeds with greater energy content (compare curves in the right-hand column of Figure 2, see also Figure 3).

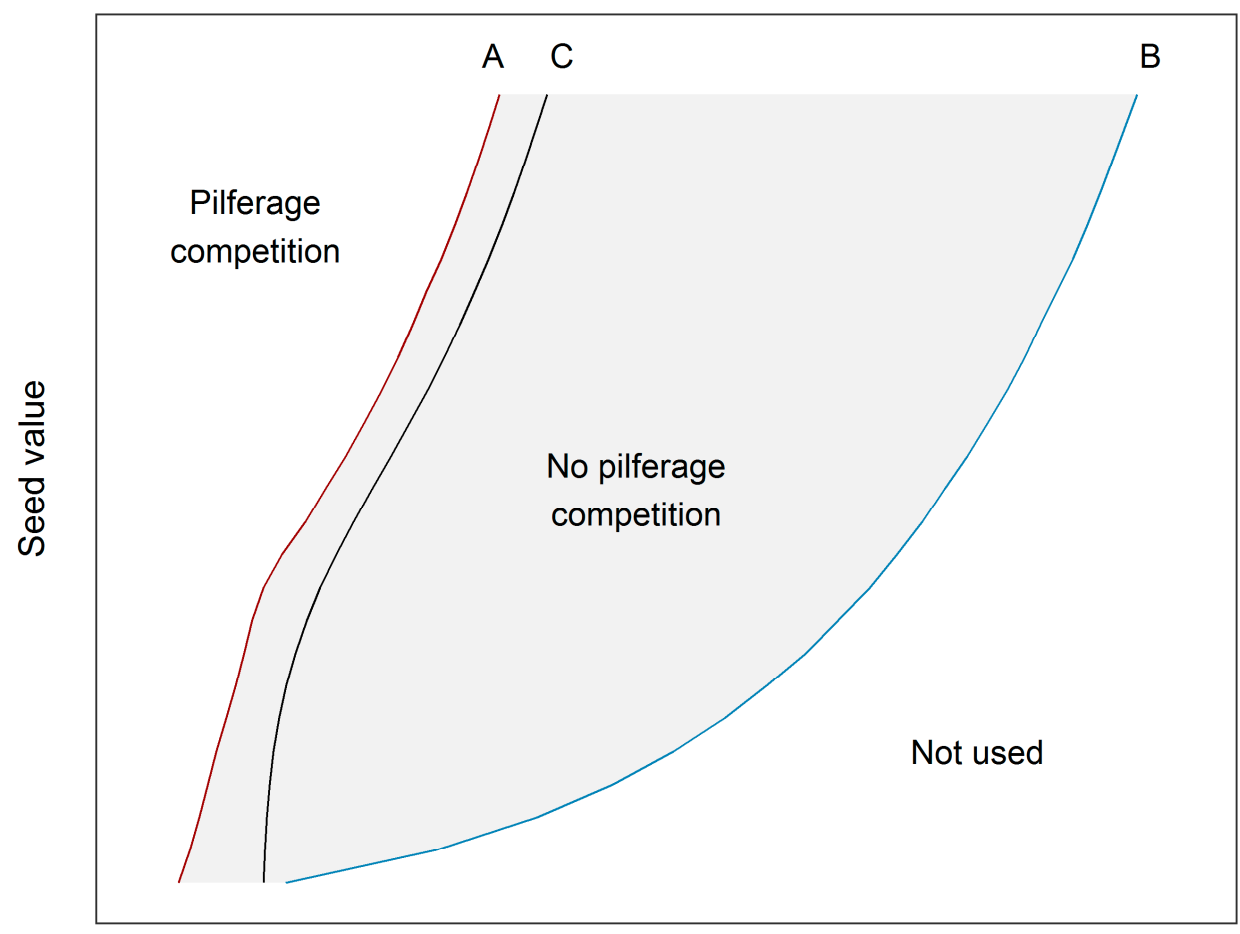

Risk coefficient

Figure 3. The phase-plane for perceived risk of foraging at a given location and the value of seeds cached at that location can be divided into three regions. Starting at the left, isopleth A (red line) marks the threshold at which the benefit of pilfering other animals' caches intersects a hypothetical giving-up rate, so that pilferers should move elsewhere or switch foraging strategies. Cache retrieval remains profitable, but pilferage is not profitable, in the shaded region between isopleths A and B (blue line). To the right of isopleth B, retrieval also becomes unprofitable. Finally, isopleth C (black line) marks the combination of seed value and risk at which recovery advantages are maximized, based on a comparison of the benefit rates for retrieval and pilferage. Importantly, all three isopleths show positive relationships between seed value and risk, indicating that greater risks are needed to protect more valuable seeds. (This graph: 0.12 caches $/ \mathrm{m}^{2}$ with $\left.g_{[i, \mathrm{eat}, \mathrm{k}]}\right]=5, g_{[\text {own,recache,kJ] }}=0.1$; curves show similar patterns for higher or lower cache densities but isopleths shift to the right or left, respectively).

\subsection{Effects of Seed Value on the Risk Level Needed to Protect a Cache}

Figures 1 and 2 show that hungry foragers who retrieve their own caches can exploit moderately risky neighborhoods where they would not be willing to accept the risks necessary to pilfer another animal's caches. As long as hoarders retrieve their caches when they are hungry, they should therefore be able to use predation risk as well as cache density to protect those caches. Figure 3 shows a phase-plane diagram for predation risk and seed energy content, with $n_{\text {own }}=0.12$ caches $/ \mathrm{m}^{2}, g_{\text {eat }}=5$, and a hypothetical giving-up rate of 0.05 units of utility/minute. Isopleths A and B in Figure 3 correspond to the points at which the benefit curves for pilfering (isopleth A) and retrieval (isopleth B) intersect the horizontal, black giving-up threshold in Figure 1. In Figure 2, they correspond to the red and blue arrows, respectively. Isopleth $C$ corresponds to the maximum of the retrieval advantage 
curve in Figure 2. All three isopleths show positive slopes, which indicate that, all else being equal, greater risks are required to protect more valuable seeds.

To the left of isopleth A, pilferage and retrieval are both viable strategies, and some level of competition is likely to exist. However, the curves in Figure 2 generally increase from left to right and cross from negative to positive values at risk levels less than or equal to the red arrows that correspond to isopleth A. Retrievers may therefore experience some protection against pilferers from increased risk, even to the right of isopleth $\mathrm{A}$. Within the shaded region between $\mathrm{A}$ and $\mathrm{B}$, conspecifics may utilize the same neighborhood, but should be focused exclusively on retrieval of their own caches, rather than searching for other individual's caches. By storing seeds in this region, hoarders can largely avoid pilferage competition. Finally, to the right of B, the neighborhood becomes too risky to be exploited under either strategy.

The precise arrangement of the risk-value isopleths in Figure 3 depends on cache density as well as forager condition and the giving-up rate. As shown in Figure 2, the giving-up thresholds (arrows) and peak retrieval advantage both shift to the left under lower cache densities. In addition, isopleth B will move closer to isopleth A if foragers retrieve their own caches when they are less hungry. As a result, the shaded area in Figure 3 will disappear if foragers retrieve caches when the benefit of eating their contents is equal to the benefit of caching new seeds. Moving in the other direction with respect to forager condition, the distance between isopleths A and B should stabilize once foragers are hungry enough that both pilferers and retrievers consistently choose to eat the seeds that they collect. Under such conditions, the differences between the strategies would be driven entirely by differences in foraging efficiency, so with increasing hunger, both isopleths should shift to the right at similar rates.

The effects of higher giving-up rates (i.e., greater values for the horizontal line in Figure 1) would depend on seed value and cache density. Under higher density conditions, isopleth B will collapse toward A until pilferage becomes the dominant strategy. At lower densities and high seed values (upper right in Figure 1), both isopleths will shift to the left, but isopleth A will move more rapidly than B.

\subsection{Seed Traits and Shade Tolerance}

If hoarders create meaningful selective pressure on plants by storing preferred seeds in well-lit, risky locations, then we should see a negative relationship between shade tolerance and hoarders' valuations of seeds. Figure 4 plots shade tolerance indices for 20 species of potentially scatter-hoarded tree against the estimated caching utility of their seeds to eastern gray squirrels. While these data are not conclusive, the pattern is reasonably inconsistent with the null hypothesis that no relationship exists, even after the removal of two potential high influence points, marked A and B. 


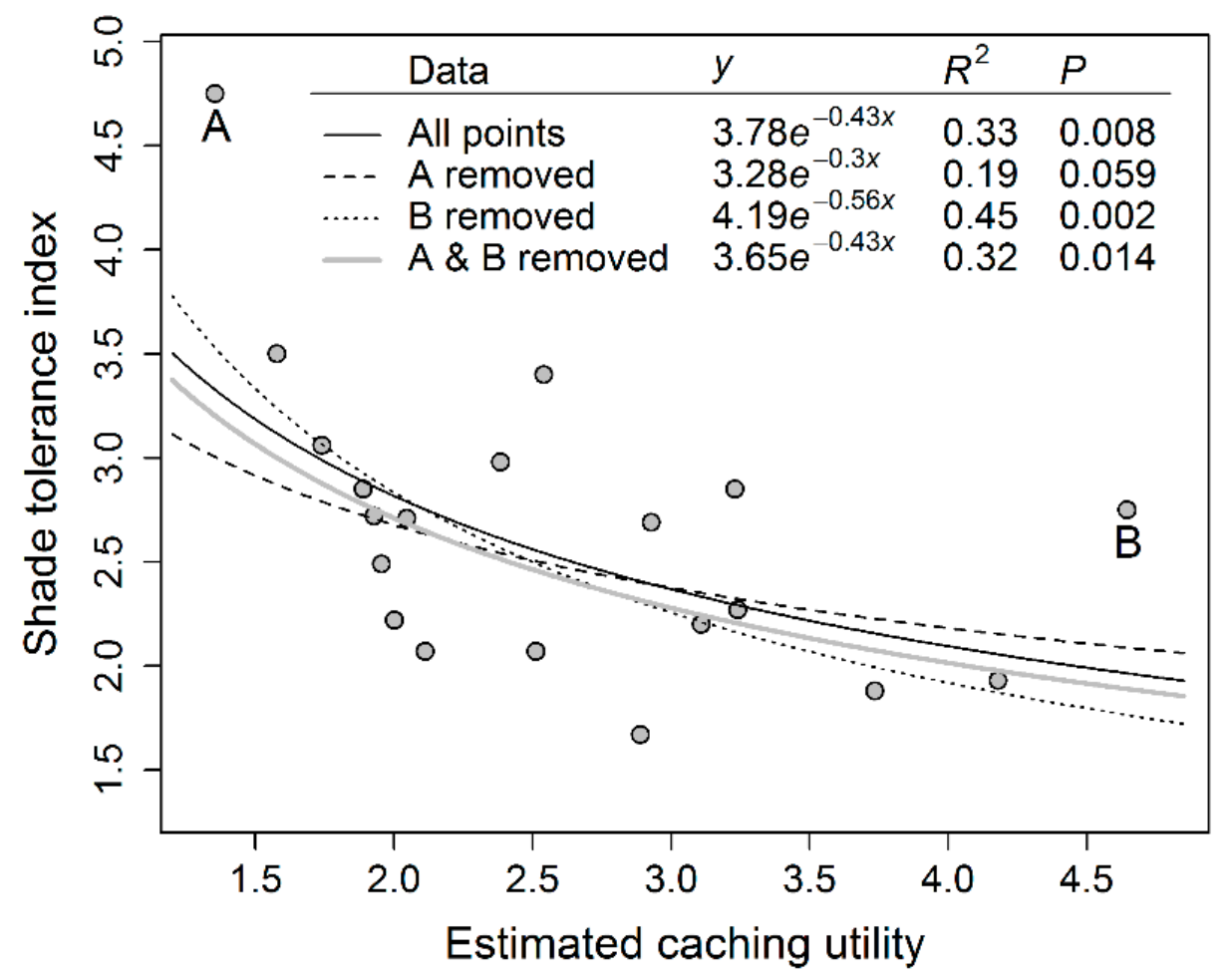

Figure 4. Shade tolerance is inversely related to the caching-utility of scatter-hoarded seeds. Caching data come from $[72,73]$ and shade tolerance data from [74]. Two data points, labeled A and B on the figure, are potential high-influence points. We therefore account for statistical relationships with and without these outliers.

\section{Discussion}

Scatter-hoarding has long been understood as a behavioral response to cache pilferage; hoarders spread caches as widely as possible, given the constraints of time and energy, in order to drive down reward rates and persistence among pilferers [52]. However, our model shows that as long as hoarders maintain some memory of their caches' locations and are able exploit those caches with greater efficiency than naive foragers are able to achieve-and as long as they primarily retrieve caches when they are hungry - spatial variation in anti-predator cover can be used to either augment or replace the effects of cache density. In fact, hoarders might achieve greater advantages by caching at slightly higher densities in moderately risky locations than by caching at lower densities in safe locations. Because retrieval is more efficient than pilferage, foragers are able to exercise greater vigilance when retrieving caches in risky environments than when pilfering in those same environments (Figure S2). As a result, hoarders that place their caches in moderately risky locations may substantially reduce pilferer's reward rates while only mildly reducing their own efficiency. In some cases, this strategy may even eliminate pilferage altogether.

More valuable seeds will increase reward rates regardless of foraging strategy. Therefore, hoarders who cache valuable seeds and aim to deter pilferers must use lower cache densities or riskier cache sites (or some combination of the two) than would be required to protect less-valued seeds. As a result, our model predicts that high-value seeds will be moved further up a risk gradient than low-value seeds, and because rodents associate open, unsheltered microhabitats with greater risk $[7,66,76]$, behaviors that transport seeds up a risk gradient will also transport them up a light gradient. All else being equal, this mechanism would direct dispersal of shade intolerant plants toward microsites that are more favorable to the establishment of their seedlings. If the resulting number of successful seedlings exceeds what would be achieved in the hoarder's absence, this would ultimately increase maternal 
fitness $[77,78]$. Assuming that the traits selected by hoarders are heritable, natural selection would therefore favor the production of seeds valued by scatter-hoarding animals.

Importantly, the mechanisms just described do not depend on any link between shade tolerance and seed traits outside of that created by the hoarder itself. The negative relationship between shade tolerance and seed value that we observe in Figure 4 is therefore a confirmation of the model's expected result, and not a validation of its assumptions.

To have the predicted evolutionary effect, the model does require that hoarders seek to minimize pilferage, that they perceive risk to vary across space, and that a reasonably strong correlation exists between the hoarder's perception of risk and a seedling's environmental requirements. Although we have focused on light requirements in this discussion, any strong correlation between a plants' needs and cache-site selection would produce a similar result. In contrast, without substantial variation in risk, which is represented on a log scale in Figures 1-3, hoarders must rely on density or other mechanisms to protect caches and would be unlikely to direct the seeds to locations that favor their establishment. Similarly, if the seedling's requirements are unrelated to the hoarder's perception of risk, then directed dispersal will not occur.

While we believe that our conclusions are robust, we have made a number of simplifying assumptions in the model and have taken a static, rather than dynamic, approach to our current analysis. Consequently, our results describe optimal foraging benefits under a range of fixed conditions. In a dynamic model, those conditions would change over time, but the forager's responses at any given point in time and space would continue to be governed by the mechanisms described in our results. Specifically, setting $\partial \theta / \partial t \propto \nabla_{\theta} U_{\text {forage }}$ and $\partial n / \partial t=f(N, \theta)$, where $\theta=[r, m, p, A, w, v]$ and $N$ is the number of foragers, and then providing for feedbacks on $g$, will allow us to model changes in forager behavior over time as a result of changing conditions due to seed harvest, consumption, and caching. In the future, we plan to use such a dynamic approach to better understand how the relationships that we describe here might affect the development of seed fate and plant population dynamics over seasonal and longer time scales.

Our current model also does not address the costs of cache establishment. At some point, the dangers of creating caches in risky sites must outweigh the benefits that those sites would provide and prevent hoarders from exploiting them. However, this appears unlikely to alter our conclusions. First, our model is already conservatively parameterized, with relatively conspicuous caches $\left(k_{\text {other }}=0.9\right)$, moderate travel speed during retrieval $(t=3 \mathrm{~m} / \mathrm{s})$, and high densities for other hoarders' caches $\left(n_{\text {other }}=5.9 \times n_{\text {own }}\right)$, all of which favor pilferage over retrieval. We also assume that foragers eat seeds in the same neighborhood where they collect them, instead of carrying them to a safer location. As a result, hungry retrievers, which have lower per-seed foraging efficiency because eating a seed takes longer than caching it, cannot mitigate their cost of fear by relocating. Yet, they are still able to obtain positive benefits at moderate risk levels because their more efficient search strategy allows greater vigilance. Finally, because the differences between retrieval and pilfering in Figure 2 initially move in a positive direction with increasing risk, the chances that a hoarder will retrieve its caches will be higher at moderate risk levels, even if the difference never becomes positive. Instead of canceling out the effects of risk, we expect the addition of establishment costs to shift isopleths A and $C$ in Figure 3 to the left, so that the advantages at a given level of hunger would be maximized at relatively lower risk levels. However, the overall patterns in our results would remain unchanged.

Although we have used energy content as a simple and convenient marker in this paper, scatter-hoarders assess seed value based on many traits, including seed size relative to the hoarder, the proportion of the seed that is made up of kernel versus shell or other inedible components, the nutritional and energy content of the edible components, the toughness of any physical defenses, the concentrations and toxicity of any chemical defenses such as tannins, alkaloids, glycosides, or saponins, and the seed's potential perishability [14]. Sundaram et al. [73] showed that eastern grey squirrels will trade different traits against each other when assessing a seed's value. As a result, many different combinations of traits can lead to similar valuations and behavioral responses. 
For example, black walnuts (Juglans nigra), which have large seeds with lipid-rich, energy-dense kernels and hard, thick shells but no chemical defenses, were found to have utility similar to northern red oak acorns, which have thinner shells, but lower lipid content, smaller overall size, and relatively high concentrations of tannins. The existence of such tradeoffs and equivalencies suggests that if hoarders do provide high quality dispersal services, they might also create a mechanism for diversification, as competition for dispersal would push different plant lineages to evolve toward different combinations of trait values depending on their initial locations in trait-space.

Of course, many of the traits that have been linked to hoarder behavior may also affect fitness through other mechanisms. Seed size and nutritional resources can benefit seedling competitiveness and survival directly [79], and physical and chemical defenses may deter insects, microbes, or other pure seed predators [80], as well as nudging hoarders toward storing seeds instead of eating them [14]. Our goal is not to imply that scatter-hoarders alone have driven these traits' evolution, but rather to demonstrate that, in theory, the combination of shade intolerance, caching behavior, and predation risk can yield selective pressures that would explain the combinations of seed and seedling phenotypes exhibited by scatter-hoarded plants.

Assuming that hoarders do take advantage of spatial memory and the landscape of fear to protect their caches, it is possible that predation on hoarders could make an underappreciated, direct contribution to seedling recruitment and plant fitness. In a small study, Steele et al. [50] live-trapped six eastern gray squirrels and held them in captivity for several weeks to simulate predation. Simultaneously, they tracked the fates of those squirrels' caches and of caches established by squirrels that remained on-site. On average, the seeds in caches established by live-trapped squirrels remained in place for at least three-times longer than control caches (20-60 days, versus 0.5-6 days for controls), and in many cases, they were disturbed only after the cache-owner's release, suggesting that when hoarders are killed by predators, their abandoned caches may remain largely undisturbed.

Presumably, hoarders' perceptions of risk are at least approximately accurate, and we would therefore expect higher mortality rates among those animals that actively cache seeds in riskier locations. Our model suggests that on average, any caches left behind by these hoarders would have lower probabilities of being discovered by pilferers, and potentially higher probabilities of producing seedlings, relative to caches established by risk-averse individuals. In shade-intolerant plants, a larger proportion of those seedlings would also be located in hospitable microsites, further increasing their probabilities of success. Thus, although hoarder mortality may be rare, such events may contribute disproportionately to the recruitment and fitness of scatter-hoarded plants. However, even if direct mortality plays only a minor role, our model suggests that shade intolerance, predators, and habitat heterogeneity may have played critical roles in the evolution of scatter-hoarding as a seed dispersal syndrome.

\section{Conclusions}

Our model demonstrates two key theoretical findings. First, retrieval allows hoarders to maintain positive foraging yields under greater levels of predation risk, relative to pilferage, and as a result, hoarders can use risk to protect their caches. Second, the level of risk that is required to maximize the retriever's advantage increases with the value of the cached food item. Taken together with the negative relationship between seed value and shade tolerance observed in Figure 4, and with previous observations of selective cache-placement in high risk locations [58-61], our results suggest that seed trait evolution in scatter-hoarded plants might be driven by the combined pressures of seedling shade intolerance and granivores' predator-mediated pilferage avoidance behaviors. Future research will aim to verify and refine these theoretical findings and to determine how the mechanisms that we have identified here operate in multispecies communities to influence the development of seed fate over time. 
Supplementary Materials: The following are available online at http://www.mdpi.com/1424-2818/12/11/416/s1, Supplement S1: Equivalence of alternative vigilance parameterizations and derivation of travel time during cache retrieval; Figure S1: Optimal benefit of foraging given a choice between retrieval and pilferage; Figure S2: Allocation of attention to vigilance at optimal foraging rates for retrieval versus pilferage; Figure S3: Allocation of seeds to caching versus consumption at optimal foraging rates for retrieval versus pilferage. Source code and parameterization files for the model and analyses are available on GitHub at: https://github.com/nlichti/Lichti_et_ al_scatterhoarding_and_predation_2020.git. Data for Figure 4 are available in [72-74].

Author Contributions: Conceptualization, N.I.L., H.J.D. and M.A.S.; Methodology, N.I.L.; Software, N.I.L.; Formal analysis, N.I.L.; Writing_-Original Draft Preparation, N.I.L.; Writing-Review and Editing, N.I.L., H.J.D. and M.A.S.; Visualization, N.I.L. All authors have read and agreed to the published version of the manuscript.

Funding: This research was partially funded by financial support to M.A.S. by the H. Fenner Endowment at Wilkes University. The APC was funded by Wilkes University.

Acknowledgments: We thank two anonymous reviewers for their comments and suggestions, which have substantially improved the manuscript.

Conflicts of Interest: The authors declare no conflict of interest.

\section{References}

1. Schupp, E.W.; Jordano, P.; Gómez, J.M. Seed dispersal effectiveness revisited: A conceptual review. New Phytol. 2010, 188, 333-353. [CrossRef] [PubMed]

2. McConkey, K.R.; Prasad, S.; Corlett, R.T.; Campos-Arceiz, A.; Brodie, J.F.; Rogers, H.; Santamaria, L. Seed dispersal in changing landscapes. Biol. Conserv. 2012, 146, 1-13. [CrossRef]

3. Janzen, D.H. Herbivores and the number of tree species in tropical forests. Am. Nat. 1970, 104, 501-528. [CrossRef]

4. Schupp, E.W. Seed seedling conflicts, habitat choice, and patterns of plant recruitment. Am. J. Bot. 1995, 82, 399-409. [CrossRef]

5. Schupp, E.W.; Fuentes, M. Spatial patterns of seed dispersal and unification of plant population ecology. Ecoscience 1995, 2, 267-275. [CrossRef]

6. Crawley, M.; Long, C. Alternate bearing, predator satiation and seedling recruitment in Quercus robur L. J. Ecol. 1995, 83, 683-696. [CrossRef]

7. Hulme, P.E.; Kollmann, J. Seed Predator Guilds, Spatial Variation in Post-Dispersal Seed Predation and Potential Effects on Plant Demography: A Temperate Perspective; Forget, P.M., Lambert, J.E., Hulme, P.E., Vander Wall, S.B., Eds.; CAB International: Wallingford, UK, 2005; pp. 9-30.

8. Darwin, C. On the action of sea-water on the germination of seeds. J. Proc. Linn. Soc. Lond. 1857, 1, 130-140.

9. Vander Wall, S.B. How plants manipulate the scatter-hoarding behaviour of seed-dispersing animals. Philos. Trans. R. Soc. B Biol. Sci. 2010, 365, 989-997. [CrossRef]

10. Zhang, Z.; Wang, Z.; Chang, G.; Yi, X.; Lu, J.; Xiao, Z.; Zhang, H.; Cao, L.; Want, F.; Li, H.; et al. Trade-off between seed defensive traits and impacts on interaction patterns between seeds and rodents in forest ecosystems. Plant Ecol. 2016, 217, 253-265. [CrossRef]

11. Levin, S.A.; Müller-Landau, H.C.; Nathan, R.; Chave, J. The ecology and evolution of seed dispersal: A theoretical perspective. Ann. Rev. Ecol. Evol. Syst. 2003, 34, 575-604. [CrossRef]

12. Thuiller, W.; Albert, C.; Araújo, M.B.; Berry, P.M.; Cabeza, A.; Guisan, M.; Hickler, T.; Midgley, G.F.; Paterson, J.; Schurr, F.M. Predicting global change impacts on plant species' distributions: Future challenges. Perspect. Plant Ecol. Evol. Syst. 2008, 9, 137-152. [CrossRef]

13. Cousens, R.D.; Hill, J.; French, K.; Bishop, I.D. Towards better prediction of seed dispersal by animals. Funct. Ecol. 2010, 24, 1163-1170. [CrossRef]

14. Lichti, N.I.; Steele, M.A.; Swihart, R.K. Seed fate and decision-making processes in scatter- hoarding rodents. Biol. Rev. 2017, 92, 474-504. [CrossRef]

15. Vander Wall, S.B. Food Hoarding in Animals; University of Chicago Press: Chicago, IL, USA, 1990; pp. 1-44.

16. Morris, D. The behaviour of the green acouchi (Myoprocta pratti) with special reference to scatter hoarding. Proc. Zool. Soc. Lond. 1962, 139, 701-732. [CrossRef]

17. Steele, M.A.; Smallwood, P.D. Acorn Dispersal by Birds and Mammals. In Oak Forest Ecosystems: Ecology and Management for Wildlife; McShea, W., Healy, W., Eds.; Johns Hopkins University Press: Baltimore, MD, USA, 2002; pp. 182-195. 
18. Price, M.V.; Jenkins, S.H. Rodents as seed consumers and dispersers. In Seed Dispersal; Murray, D.R., Ed.; Academic Press: Sydney, Australia, 1986; pp. 191-235.

19. Vander Wall, S.B. The evolutionary ecology of nut dispersal. Bot. Rev. 2001, 67, 74-117. [CrossRef]

20. Shimada, T. Hoarding behaviors of two wood mouse species: Different preference for acorns of two Fagaceae species. Ecol. Res. 2001, 16, 127-133. [CrossRef]

21. Klinger, R.; Rejmánek, M. The numerical and functional responses of a granivorous rodent and the fate of Neotropical tree seeds. Ecology 2009, 90, 1549-1563. [CrossRef]

22. Lichti, N.I.; Steele, M.A.; Zhang, H.; Swihart, R.K. Mast species composition alters seed fate in North American rodent-dispersed hardwoods. Ecology 2014, 95, 1746-1758. [CrossRef]

23. Sivy, K.J.; Ostoja, S.M.; Schupp, E.W.; Durham, S. Effects of rodent species, seed species, and predator cues on seed fate. Acta Oecol. 2011, 37, 321-328. [CrossRef]

24. Jansen, P.A.; Bongers, F.; Hemerik, L. Seed mass and mast seeding enhance dispersal by a neotropical scatter-hoarding rodent. Ecol. Monogr. 2004, 74, 569-589. [CrossRef]

25. Galvez, D.; Kranstauber, B.; Kays, R.W.; Jansen, P.A. Scatter hoarding by the Central American agouti: A test of optimal cache spacing theory. Anim. Behav. 2009, 78, 1327-1333. [CrossRef]

26. Perea, R.; San Miguel, A.; Martínez-Jauregui, M.; Valbuena-Carabaña, M.; Gil, L. Effects of seed quality and seed location on the removal of acorns and beechnuts. Eur. J. For. Res. 2012, 131, 623-631. [CrossRef]

27. Wang, B.; Chen, J. Effects of fat and protein levels on foraging preferences of tannin in scatter- hoarding rodents. PLoS ONE 2012, 7, e40640. [CrossRef] [PubMed]

28. Xiao, Z.; Zhang, Z.; Wang, Y. Dispersal and germination of big and small nuts of Quercus serrata in a subtropical broad-leaved evergreen forest. For. Ecol. Manag. 2004, 195, 141-150. [CrossRef]

29. Cheng, J.; Xiao, Z.; Zhang, Z. Seed consumption and caching on seeds of three sympatric tree species by four sympatric rodent species in a subtropical forest, China. For. Ecol. Manag. 2005, 216, 331-341. [CrossRef]

30. Vander Wall, S.B. Effects of seed size of wind dispersed pines (Pinus) on secondary seed dispersal and the caching behavior of rodents. Oikos 2003, 100, 25-34. [CrossRef]

31. Yi, X.; Yang, Y. Scatterhoarding of Manchurian walnut (Juglans mandshurica) by small mammals: Response to seed familiarity and seed size. Acta Theriol. 2011, 56, 141-147. [CrossRef]

32. Yi, X.; Yang, Y.; Zhang, Z. Intra-and inter-specific effects of mast seeding on seed fates of two sympatric Corylus species. Plant Ecol. 2011, 212, 785-793. [CrossRef]

33. Hadj-Chikh, L.Z.; Steele, M.A.; Smallwood, P.D. Caching decisions by grey squirrels: A test of the handling time and perishability hypotheses. Anim. Behav. 1996, 52, 941-948. [CrossRef]

34. Steele, M.A.; Wauters, W.A.; Larsen, K.W. Selection, predation and dispersal of seeds by tree squirrels in temperate and boreal forests: Are tree squirrels keystone granivores? In Seed Fate: Predation, Dispersal, and Seedling Establishment; Forget, P.-M., Lambert, J.E., Hulme, P.E., Vander Wall, S.B., Eds.; CAB International: Cambridge, MA, USA, 2005; pp. 205-221.

35. Moore, J.E.; McEuen, A.B.; Swihart, R.K.; Contreras, T.A.; Steele, M.A. Determinants of seed removal distance by scatter-hoarding rodents in deciduous forests. Ecology 2007, 88, 2529-2540. [CrossRef]

36. Steele, M.A. Evolutionary Interactions between Tree Squirrels and Trees: A Review and Synthesis. Curr. Sci. 2008, 10, 871-876.

37. Xiao, Z.; Gao, X.; Jiang, M.; Zhang, Z. Behavioral adaptation of Pallas's squirrels to germination schedule and tannins in acorns. Behav. Ecol. 2009, 20, 1050-1055. [CrossRef]

38. Xiao, Z.; Gao, X.; Zhang, Z. The combined effects of seed perishability and seed size on hoarding decisions by Pére David's rock squirrels. Behav. Ecol. Sociobiol. 2013, 67, 1067-1075. [CrossRef]

39. Wang, B.; Corlett, R.T. Scatter-hoarding rodents select different caching habitats for seeds with different traits. Ecosphere 2017, 8. [CrossRef]

40. Wang, B.; Ye, C.-X.; Cannon, C.H.; Chen, J. Dissecting the decision making process of scatter- hoarding rodents. Oikos 2013, 122, 1027-1034. [CrossRef]

41. Sundaram, M.; Lichti, N.I.; Steele, M.A.; Dalgleish, H.J.; Swihart, R.K. Frequency-dependent hoarding by Sciurus carolinensis occurs with seeds of similar perceived value. J. Mammal. 2017, 98, 124-134.

42. Andersson, M.; Krebs, J.R. On the evolution of hoarding behavior. Anim. Behav. 1978, 26, 707-711. [CrossRef]

43. Vander Wall, S.B.; Jenkins, S.H. Reciprocal pilferage and the evolution of food-hoarding behavior. Behav. Ecol. 2003, 14, 656-667. [CrossRef] 
44. Kamil, A.C.; Gould, K.L. Memory in Food Caching Animals. In Learning and Memory: A Comprehensive Reference. In Learning Theory and Behaviour; Menzel, R., Byrne, J.H., Eds.; Elsevier Ltd.: Amsterdam, The Netherlands, 2008; pp. 419-439.

45. Brodin, A. The history of scatter-hoarding studies. Philos. Trans. R. Soc. B Biol. Sci. 2010, 365, 869-881. [CrossRef]

46. Hirsch, B.; Kays, R.; Jansen, P. Evidence for cache surveillance by a scatter-hoarding rodent. Anim. Behav. 2013, 85, 1511-1516. [CrossRef]

47. Bartlow, A.W.; Lichti, N.; Curtis, R.; Swihart, R.; Steele, M.A. Re-caching of acorns by rodents: Cache management in eastern deciduous forests of North America. Acta Oecol. 2018, 92, 117-122. [CrossRef]

48. Jacobs, L.F. Memory for cache locations in Merriam's kangaroo rats. Anim. Behav. 1992, 43, 585-593. [CrossRef]

49. Jacobs, L.F.; Liman, E.R. Grey squirrels remember the locations of buried nuts. Anim. Behav. 1991, 41, $103-110$. [CrossRef]

50. Steele, M.A.; Bugdal, M.; Yuan, A.; Bartlow, A.; Buzalewski, J.; Lichti, N.; Swihart, R. Cache placement, pilfering, and a recovery advantage in a seed-dispersing rodent: Could predation of scatter hoarders contribute to seedling establishment? Acta Oecol. 2011, 37, 554-560. [CrossRef]

51. Jansen, P.A.; Hirsch, B.T.; Emsens, W.J.; Zamora-Gutierrez, V.; Wikelski, M.; Kays, R. Thieving rodents as substitute dispersers of megafaunal seeds. Proc. Natl. Acad. Sci. USA 2012, 109, 12610-12615. [CrossRef] [PubMed]

52. Stapanian, M.A.; Smith, C.C. A model for seed scatterhoarding: Coevolution of fox squirrels and black walnuts. Ecology 1978, 59, 884-896. [CrossRef]

53. Stapanian, M.A.; Smith, C.C. Density-dependent survival of scatterhoarded nuts: An experimental approach. Ecology 1984, 65, 1387-1396. [CrossRef]

54. Hirsch, B.T.; Kays, R.; Pereira, V.E.; Jansen, P.A. Directed seed dispersal towards areas with low conspecific tree density by a scatter-hoarding rodent. Ecol. Lett. 2012, 15, 1423-1429. [CrossRef] [PubMed]

55. Briggs, J.S.; Vander Wall, S.B. Substrate type affects caching and pilferage of pine seeds by chipmunks. Behav. Ecol. 2004, 15, 666-672. [CrossRef]

56. Brown, J.S. Patch use as an indicator of habitat preference, predation risk, and competition. Behav. Ecol. Sociobiol. 1988, 22, 37-47. [CrossRef]

57. Brown, J.S.; Kotler, B.P. Hazardous duty pay and the foraging cost of predation. Ecol. Lett. 2004, 7, 999-1014. [CrossRef]

58. Preston, S.D.; Jacobs, L.F. Cache decision making: The effects of competition on cache decisions in Merriam's kangaroo rat (Dipodomys merriami). J. Comp. Psychol. 2005, 119, 187-196. [CrossRef] [PubMed]

59. Muñoz, A.; Bonal, R. Linking seed dispersal to cache protection strategies. J. Ecol. 2011, 99, 1016-1025. [CrossRef]

60. Steele, M.A.; Contreras, T.A.; Hadj-Chikh, L.Z.; Agosta, S.J.; Smallwood, P.D.; Tomlinson, C.N. Do scatter hoarders trade off increased predation risks for lower rates of cache pilferage? Behav. Ecol. 2014, 25, $206-215$. [CrossRef]

61. Steele, M.; Rompré, G.; Stratford, J.; Zhang, H.; Suchocki, M.; Marino, S. Scatter-hoarding rodents favor higher predation risks for cache sites: The potential for predators to influence the seed dispersal process. Integr. Zool. 2015, 10, 257-266. [CrossRef]

62. Holling, C.S. The components of predation as revealed by a study of small mammal predation of the European pine sawfly. Can. Ent. 1959, 91, 293-320. [CrossRef]

63. Brown, J.S. Vigilance, patch use and habitat selection: Foraging under predation risk. Evol. Ecol. Res. 1999, 1, 49-71.

64. Dukas, R.; Ellner, S. Information processing and prey detection. Ecology 1993, 74, 1337-1346. [CrossRef]

65. Kotler, B.P.; Brown, J.S.; Hickey, M. Food storability and the foraging behavior of fox squirrels (Sciurus niger). Am. Midl. Nat. 1999, 142, 77-86. [CrossRef]

66. Luttbeg, B.; Ferrari, M.C.O.; Blumstein, D.T.; Chivers, D.P. Safety cues can give prey more valuable information than danger cues. Am. Nat. 2020, 195, 636-648. [CrossRef] [PubMed]

67. Jones, K.E.; Bielby, J.; Cardillo, M.; Fritz, S.A.; O’Dell, J.; Orme, C.D.L.; Safi, K.; Sechrest, W.; Boakes, E.H.; Carbone, C.; et al. PanTHERIA: A species-level database of life history, ecology, and geography of extant and recently extinct mammals. Ecology 2009, 90, 2648. [CrossRef] 
68. R Core Team R: A Language and Environment for Statistical Computing; R Foundation for Statistical Computing: Vienna, Austria, 2020; Available online: https://www.R-project.org/ (accessed on 1 June 2020).

69. Byrd, R.H.; Lu, P.; Nocedal, J.; Zhu, C.A. limited memory algorithm for bound constrained optimization. SIAM J. Sci. Comp. 1995, 16, 1190-1208. [CrossRef]

70. Mullen, K.M.; Ardia, D.; Gil, D.; Windover, D.; Cline, J. DEoptim: An R Package for Global Optimization by Differential Evolution. J. Stat. Softw. 2011, 40,1-26. [CrossRef]

71. Charnov, E.L. Optimal foraging: The marginal value theorem. Theor. Popul. Biol. 1976, 9, 129-136. [CrossRef]

72. Sundaram, M.; Willoughby, J.R.; Lichti, N.I.; Steele, M.A.; Swihart, R.K. Segregating the effects of seed traits and common ancestry of hardwood trees on eastern gray squirrel foraging decisions. PLoS ONE 2015, 10, e0130942. [CrossRef]

73. Sundaram, M.; Lichti, N.I.; Widmar, N.O.; Swihart, R.K. Insights from an application of discrete choice experiments: Eastern gray squirrels are consistent shoppers of seed traits. Integr. Zool. 2018, 13, 280-296. [CrossRef]

74. Niinemets, Ü.; Valladares, F. Tolerance to shade, drought, and waterlogging of temperate northern hemisphere trees and shrubs. Ecol. Monogr. 2006, 76, 521-547. [CrossRef]

75. McNamara, J.M.; Houston, A.I. Partial preferences and foraging. Anim. Behav. 1987, 35, 1084-1099. [CrossRef]

76. Lima, S.L. Stress and decision making under the risk of predation: Recent developments from behavioral, reproductive, and ecological perspectives. Adv. Study Behav. 1998, 27, 215-290.

77. Theimer, T.C. Rodent scatterhoarders as conditional mutualists. In Seed Fate: Predation, Dispersal and Seedling Establishment; Forget, P.M., Lambert, J.E., Hulme, P.E., Vander Wall, S.B., Eds.; CAB International: Wallingford, UK, 2005; pp. 283-296.

78. Zwolak, R.; Crone, E.E. Quantifying the outcome of plant-granivore interactions. Oikos 2012, 121, 20-27. [CrossRef]

79. Moles, A.T.; Westoby, M. Seed size and plant strategy across the whole life cycle. Oikos 2006, 113, 91-105. [CrossRef]

80. Dalling, J.W.; Davis, A.S.; Schutte, B.J.; Arnold, A.E. Seed survival in soil: Interacting effects of predation, dormancy and the soil microbial community. J. Ecol. 2011, 99, 89-95. [CrossRef]

Publisher's Note: MDPI stays neutral with regard to jurisdictional claims in published maps and institutional affiliations.

(C) 2020 by the authors. Licensee MDPI, Basel, Switzerland. This article is an open access article distributed under the terms and conditions of the Creative Commons Attribution (CC BY) license (http://creativecommons.org/licenses/by/4.0/). 